\title{
Monitoring Suhu Kelembaban dan Polusi Udara Berbasis Raspberry Pi 3 dengan Menggunakan Transmisi Radio Frekuensi
}

\author{
Husnibes Muchtar ${ }^{1}$, Rahmat Sabar Hakiki ${ }^{2}$ \\ 1) 2) Teknik Elektro Universitas Muhammadiyah Jakarta \\ Jl. Cempaka Putih Tengah 27 \\ Email: ${ }^{1)}$ husnibes.muchtar@ftumj.ac.id ${ }^{2)}$ 2015420013@ftumj.ac.id
}

\begin{abstract}
ABSTRAK
Perkembangan ilmu pengetahuan teknologi saaat ini di tandai dengan bermunculan nya alatalat yang menggunakan sistem kontrol digital dan otomatis, teknologi menjadi hal yangan sangat berguna bagi kehidupan manusia, mulai dari teknologi mekanik, listrik dan komunikasi yang sangat membantu aktivitas manusia agar lebih mudah dan lebih efisien.Penggunaan teknologi komunikasi sistem kontrol dan monitoring. Dalam hal ini pengontrolan menggunakan Handy talky sebagai komunikasi dan raspberry PI 3 sebagai pengontrolnya. Sensor untuk mendeteksi lingkungan sekitar dan LCD untuk menampilkan hasil sensor.
\end{abstract}

Kata kunci: frekuensi, shift, keying, IC 2206, IC 2211, hand, talky

\begin{abstract}
The development of science technology today is marked by the emergence of tools that use digital and automatic control systems, technology becomes a very useful thing for human life, ranging from mechanical, electrical and communication technologies that greatly help human activities to make it easier and more efficient. Use of communication technology control and monitoring systems. In this case the control uses Handy Talky as communication and Raspberry PI 3 as the controller. Sensors to detect the surrounding environment and LCD to display sensor results.
\end{abstract}

Keywords : frequency, shift, keying, IC 2206, IC 2211, hand, talky

\section{PENDAHULUAN}

Kemajuan teknologi saait ini terus berkembang dan diikuti oleh hampir semua kalangan [1]. Kebutuhan manusia untuk informasi data mencakup banyak hal, salah satunya memantau suatu objek atau lingkungan dari jarak yang cukup jauh namun dengan media Internet tidak jarang, eror dan noise dalam penggunaan. Maka dibutuhkan dalam Pemantauan suatu objek media transmisi data akan tetap stabil . Pada proses transaksi data baik pada tranmisi maupun penerima sangat dibutuhkan di era globalisasi ini [2]. Maka dibutuhkanlah pengiriman data yang efektif dan efisien yaitu menggunakan perangkat HT (Handy Talky) [3]. Pada Penelitian ini, dirancang sistem Monitoring suhu dan kelembapan Lingkungan dengan sensor DHT 22 dan MQ-135 menggunakan mikrokontroler Raspberry PI 3 yang dihubungkan ke radio modem perangkat HT (Handy Talking) . Radio modem ini menggunakan IC RX 2206 sebagai modulator dan IC RX2211 demodulator. Metode yang akan digunakan adalah modulasi dengan menggunakan sinyal Frequency Shift Keying (FSK).Mikrokontoler Raspberry PI 3 ini digunakan sebagai memonitoring suhu, kelembapan dan polusi udara yang diterima dari Sensor, hasil di tampilkan dalam Monitor. Dalam monitoring suatu lingkungan dalam pengirimaninformasi data dari jarak jauh sering kali eror atau invalid dalam pengiriman menggunakan internet Maka di butuhkan dalam Pemantauan suatu objek media transmisi data yang tetap atau stabil .Maka dibutuhkanlah pengiriman data yang relatif murah dan efisien yaitu menggunakan perangkat HT (Handy talky). Untuk tetap dipembahasan permasalahan utama, maka dalam melakukan penelitian ini dilakukan pembatasan masalah, supaya tetap dalam pokok pembahasan pada :

1. Merancang dan memonitor dengan sistem Frequensy Shift Keying, MODEM IC RX2206, MODEM IC RX 2211

2. Penggunaan Arduino (input) dan Raspberry PI 3 (output) pemograman

3. Merealisasikan Data sensor yang dikirim Modulator kepada penerima demodulator (Handy talky) dapat diterima dan di tampilkan dalam Monitor dengan Baik

Tujuan dalam penelitian ini adalah penerapan penggunaan Frequensy Shift Keying (FSK) pada Raspberry Pi dan Handy Talky dalam Memonitor Suhu Kelembapan dan Polusi Udara

\section{LANDASAN TEORI}


RESISTOR (Elektronika Kendali Telekomunikasi Tenaga Listrik Komputer) Vol. 3 No. 2 e-ISSN : 2621-9700, p-ISSN : 2654-2684

Frekuensi adalah jumlah getaran yang dihasilkan setiap 1 detik. Sedangkan dalam ilmu elektronika, Frekuensi juga dapat diartikan sebagai jumlah gelombang listrik yang dihasilkan tiap detik. Frekuensi dilambangkan dengan huruf satuannya adalah Hertz atau biasa kita ketahui dengan Hz. Jadi pada dasarnya 1 Hertz sama dengan satu getaran satu detik nya (1 Hertz = 1 gelombang per detik).

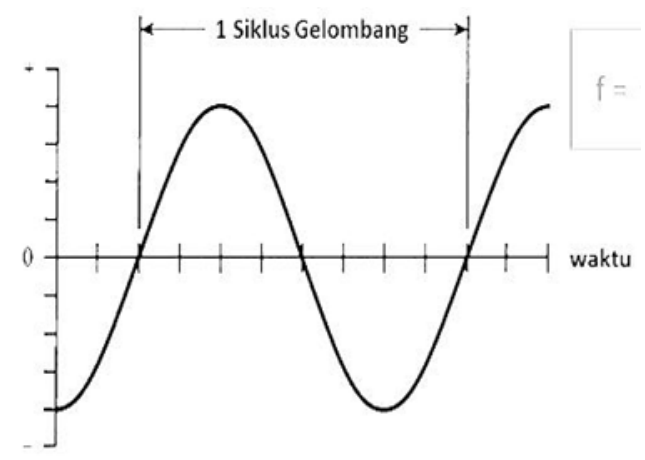

Gambar 1 Siklus gelombang hertz.

Cara menghitung frekuensi, seseorang menetapkan jarak, waktu, dan menghitung jumlah kejadian peristiwa lalu membagi hitungan ini dengan panjang jarak dan waktu. Pada Sistem Satuan Internasional, hasil perhitungan ini dinyatakan dalam satuan hertz $(\mathrm{Hz})$ yaitu yang menemukan fenomena ini pertama kali pakar fisika Jerman Heinrich Rudolf Hertz . Frekuensi sebesar $1 \mathrm{~Hz}$ adalah peristiwa yang terjadi satu kali per detik.

$$
f=\frac{1}{t}
$$

Selain itu frekuensi berhubungan dengan jumlah getaran dengan rumusan:

$$
f=\frac{n}{t}
$$

$$
\begin{aligned}
& \mathrm{f}=\text { frekuensi } \\
& \mathrm{n}=\text { getaran } \\
& \mathrm{t}=\text { detik }
\end{aligned}
$$

Modulasi diartikan sebagai perubahan suatu gelombang periodik sehingga menjadi suatu sinyal yang mampu membawa suatu informasi. Untuk dapat mengirimkan suatu informasi dari suatu perangkat ke perangkat lainnya yang menggunakan Teknologi Frekuensi Radio. Modulasi digital proses penumpangan sinyal digital (bit ) ke dalam sinyal carrier. Moduilasi digital modulasi yang mengubah karakteristik dan sifat gelombang pembawa yang biasa di sebut (carrier) sedemikian rupa sehingga bentuk hasilnya (modulated carrier) memiliki ciri-ciri dari bit-bit (0 atau 1) yang dikandungnya. Modulasi Frekuensi merupakan teknik pengiriman informasi berbentuk frekuensi rendah dengan memodulasi frekuensi gelombang pembawa yang berfrekuensi tinggi. Pada Modulasi Frekuensi FSK sinyal informasi akan mengubah frekuensi gelombang pembawanya sedangkan Amplitudonya akan tetap sama selama proses modulasi. Metode FSK dipakai karena amplitudonya stabil dan frekuensinya dapat diubah - ubah sehingga tahan noise [4]. Penyetelan ulang terhadap modulator pada APRS meliputi dua hal, yaitu secara perangkat keras (hardware) dan perangkat lunak (software) [5].

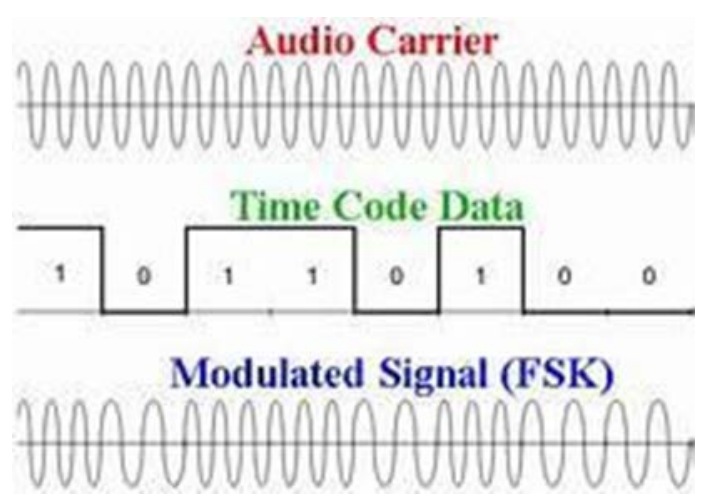

Gambar 2 Signal informasi dan signal FSK.

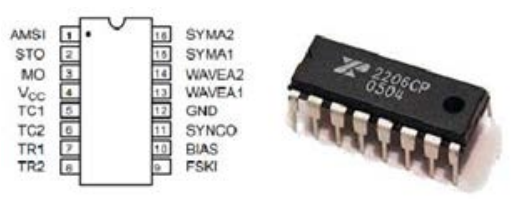

Gambar 3 IC XR-2206.

XR2206 adalah IC XR2206 yang berfungsi sebagai pembangkitkan sinyal dengan stabilitas tinggi dan akurat. IC buatan EXAR banyak digunakan untuk rangkaian signal function generator. Pin 16 adalah keluaran bentuk gelombang dimana amplitudo dan frekuensi dapat dimodulasi oleh tegangan eksternal. Frekuensi yang dihasilkan mulai dari $0.01 \mathrm{~Hz}$ sampai lebih besar dari $1 \mathrm{MHz}$. sedangkan tegang catu daya hanya $=10$ volt -26 volt.

XR2206 Terdiri dari 4 blok rangkaian yaitu : Voltage Control Oscilator, Pengali bentuk Gelombang Sinus, Penguat signal dan Pengatur Arus . VCO yang menghasilkan signal sebanding dengan masukannya yang diatur tahanan pewaktu. 
RESISTOR (Elektronika Kendali Telekomunikasi Tenaga Listrik Komputer) Vol. 3 No. 2 e-ISSN : 2621-9700, p-ISSN : 2654-2684

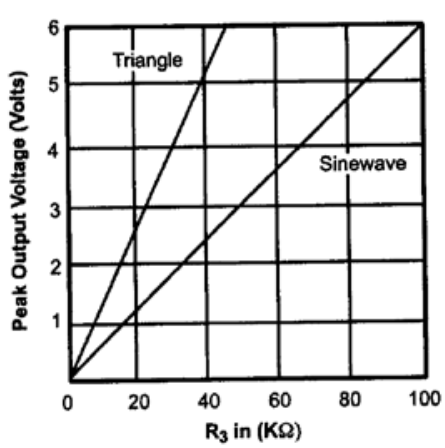

Gambar 4 Keluaran amplitudo sebagai fungsi Resistor, R3.

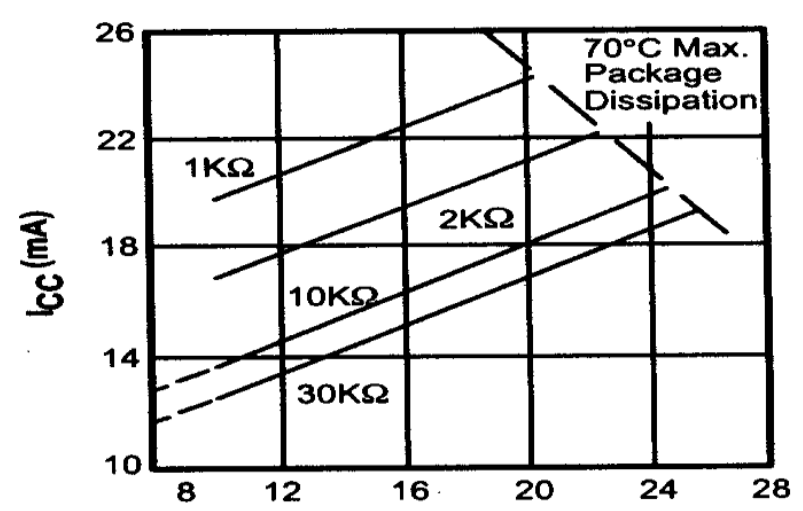

Gambar 5 Grafik arus vs tegangan catu daya, pewaktu resistor.

Tabel 1 Keterangan Pin XR-2206.

\begin{tabular}{|c|c|c|l|}
\hline Pin & Simbol & Type & \multicolumn{1}{|c|}{ Keterangan } \\
\hline 1 & AMS I & I & $\begin{array}{l}\text { Amplitude Modulating } \\
\text { Signal Input }\end{array}$ \\
\hline 2 & STO & O & $\begin{array}{l}\text { Sine and Triangle Wave } \\
\text { Output }\end{array}$ \\
\hline 3 & MO & O & Multiplier Output \\
\hline 4 & V $_{\mathrm{cc}}$ & & Positive Power Supply \\
\hline 5 & TC1 & I & Timing Capacitor Input \\
\hline 6 & TC2 & I & Timing Capasitor Input \\
\hline 7 & TR1 & O & Timing Resistor 1 Output \\
\hline 8 & TR2 & O & Timing Resistor 2 Output \\
\hline 9 & FSKI & I & $\begin{array}{l}\text { Frequency Shift Keying } \\
\text { Input }\end{array}$ \\
\hline 10 & BIAS & O & Internal Voltage Reference \\
\hline 11 & SYNCO & O & Sync Output \\
\hline 12 & GND & & Ground Pin \\
\hline 13 & WAVEA1 & I & Wave Form Adjust Input 1 \\
\hline 14 & WAVEA2 & I & Wave Form Adjust Input 2 \\
\hline 15 & SYMA1 & I & Wave Symetry Adjust 1 \\
\hline 16 & SYMA2 & I & Wave Symetry Adjust 2 \\
\hline
\end{tabular}

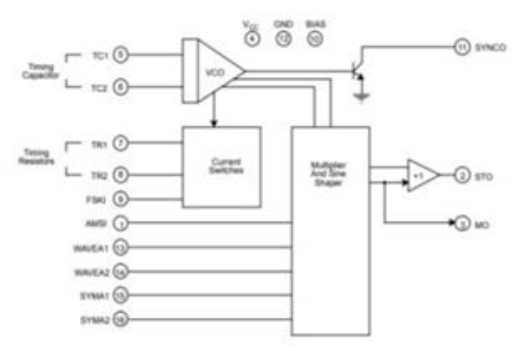

Gambar 6 Blok diagram XR-2206.

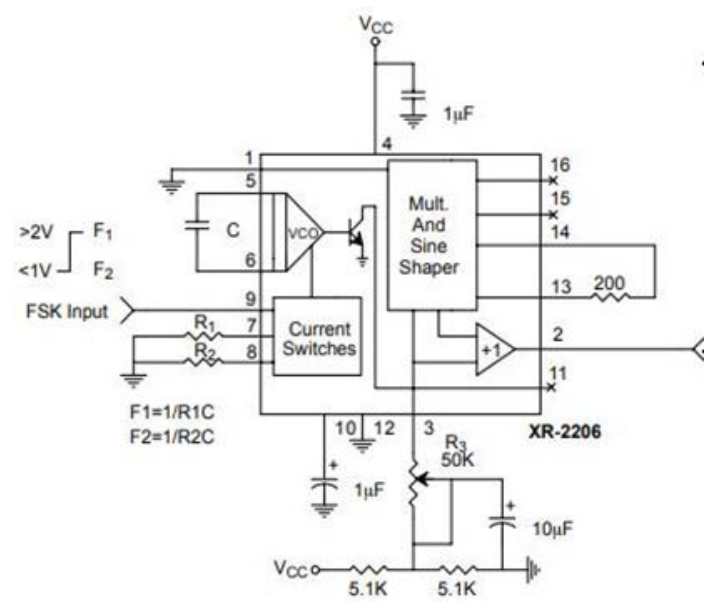

Gambar 7 Gambar Rangkaian Frequensi. 
RESISTOR (Elektronika Kendali Telekomunikasi Tenaga Listrik Komputer) Vol. 3 No. 2 e-ISSN : 2621-9700, p-ISSN : 2654-2684

IC XR-2206 berfungsi sebagai Frekuensi Shift Key (FSK) yang digunakan dalam pengiriman data. Keluaran yang dihasilkan merupakan sinyal FM (Frequency Modulation). Pada gambar terlihat bahwa frekuensi osilasi tergantung pada R1 dan R2 yang terhubung dengan pin 7 dan 8. Bila pin 9 adalah rangkaian terbuka dan dihubungkan dengan tegangan 2 volt, maka yang aktif hanya R1. Dan bila tegangan pada pin 9 adalah 1 volt maka yang aktif adalah R2. Dengan demikian frekuensi pada keluaran terkunci pada daerah frekuensi antara $\mathrm{f} 1$ dan $\mathrm{f} 2$, di mana : f1 = $1 / \mathrm{R} 1$. C dan $\mathrm{f} 2=1 / \mathrm{R} 2$. C.

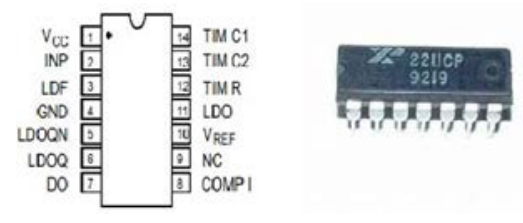

Gambar 8 IC XR-2211.

XR-2211 adalah loop fase terkunci terkunci (PLL) monolitik sistem yang dirancang khusus untuk komunikasi data aplikasi. Ini sangat cocok untuk modem FSK aplikasi. Ini beroperasi pada kisaran tegangan suplai yang luas dari 4,5 hingga 20V dan rentang frekuensi yang luas antara

Tabel 2 Keterangan Pin XR-2211.

\begin{tabular}{|c|c|c|c|}
\hline Pin & Symbol & Type & Description \\
\hline 1 & Vcc & & Positive Power supply \\
\hline 2 & INP & $\mathrm{I}$ & Receive Analog Input \\
\hline 3 & LDF & $\mathrm{O}$ & Lock Detect Filter \\
\hline 4 & GND & & Ground Pin \\
\hline 5 & LDOQN & $\mathrm{O}$ & Lock Detect Output Not \\
\hline 6 & LDOQ & $\mathrm{O}$ & Lock Detect Output \\
\hline 7 & DQ & $\mathrm{O}$ & Data Output \\
\hline 8 & COMP I & I & FSK Comparator Input \\
\hline 9 & NC & & Not Connected \\
\hline 10 & Vref & $\mathrm{O}$ & $\begin{array}{ll}\text { Internal } & \text { Voltage } \\
\text { Reference } & \end{array}$ \\
\hline 11 & LDO & $\mathrm{O}$ & Loop Detect Output \\
\hline 12 & TIM R & $\mathrm{I}$ & Timing Resistor Input \\
\hline 13 & Tim C2 & I & $\begin{array}{l}\text { The timing resistor } \\
\text { connect between this pin } \\
\text { and pin } 14\end{array}$ \\
\hline 14 & TIM C1 & I & $\begin{array}{l}\text { The timing resistor } \\
\text { connect between this pin } \\
\text { and pin } 13\end{array}$ \\
\hline
\end{tabular}

PLL utama dalam XR-2211 dibangun dari sebuah input preamplifier, pengali analog yang digunakan sebagai fase detektor dan osilator dikendalikan tegangan presisi (VCO). Preamplifier digunakan sebagai pembatas sedemikian rupa sinyal input di atas biasanya $10 \mathrm{mV}$ rms diamplifikasi menjadi sinyal tingkat tinggi konstan. Komparator FSK digunakan untuk menentukan apakah VCO didorong di atas atau di bawah frekuensi pusat (FSK pembanding). Ini akan menghasilkan tinggi aktif dan output rendah aktif untuk menunjukkan ketika PLL utama terkunci (detektor fase quadrature dan detektor kunci pembanding).
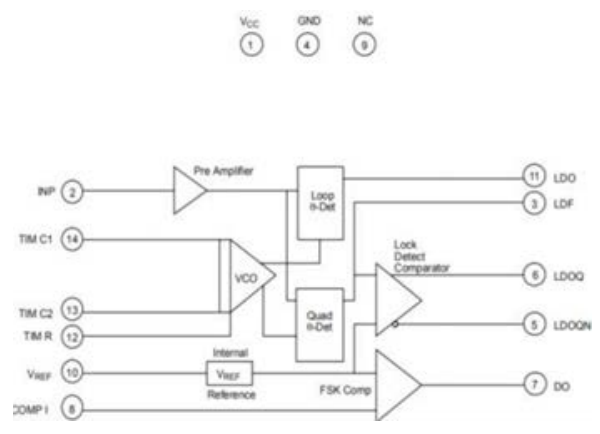

Gambar 9 Block Diagram XR-2211.

Rangkaian demodulator FSK meenerima sinyal yang berasal dari receiver. Demodulator FSK memakai IC XR2211 yang befungsi mengembalikan data kebentuk aslinya [6]. Ketika signal pada waktu dipancarkan, sinyal ini berupa sinyal sinusiodal yang akan berubah-ubah frekuensinya sesuai dengan data yang dikirimkan. Selanjutnya akan mengubah kembali sinyal sinusoidal tersebut menjadi sinyal digital (biner) yang akan menghasilkan output logika high, sedangkan frekuensi input yang kurang dari frekuensi tengah akan menghasilkan output logika low. Pada rangkaian Bell 202 Format merupakan contoh rangkaian demodulator FSK yang bekerja pada frekuensi f1 = $1200 \mathrm{~Hz}$ dan f2 $=2200 \mathrm{~Hz}$ dengan kemampuan mengirim data 1200 baud

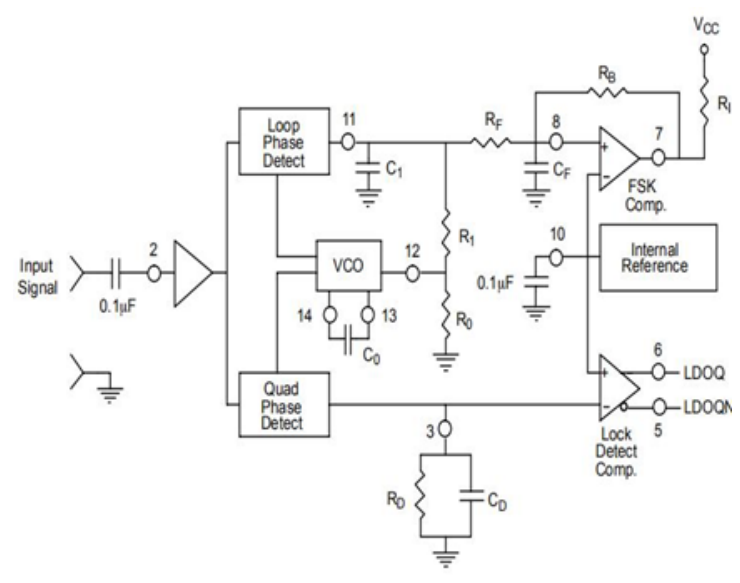


RESISTOR (Elektronika Kendali Telekomunikasi Tenaga Listrik Komputer) Vol. 3 No. 2 e-ISSN : 2621-9700, p-ISSN : 2654-2684

Gambar 10 Rangkaian frequensi shift keying demodulator.

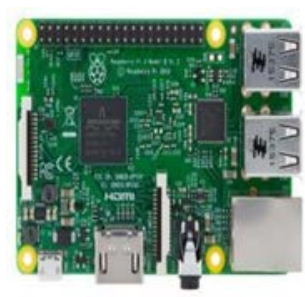

RASPBERRYPI3-MODB-1GB

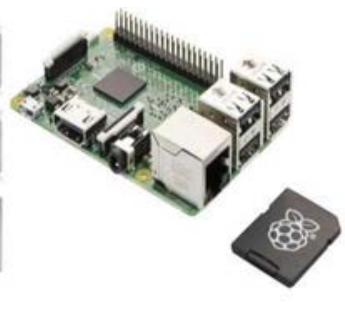

RP13-MOOB-16G8-NOOBS
Gambar 11 Raspberry Pi 3.

Raspberry Pi 3, Disebut juga Raspi, adalah komputer papan tunggal (single-board circuit; SBC) yang berukuran sama dengan kartu kredit yang dapat digunakan untuk menjalankan berbagai macam program Raspberry Pi dikembangkan oleh yayasan nirlaba, Rasberry Pi Foundation, sejumlah pengembang dan ahli komputer dari Universitas Cambridge, Inggris.

Menurut saya sendiri Raspberry Pi adalah sebuah computer kecil yang mampu menjalankan berbagai macam fungsi layaknya komputer yang dapat mengeksekusi program dan aplikasi sesuai keinginan penggunanya.

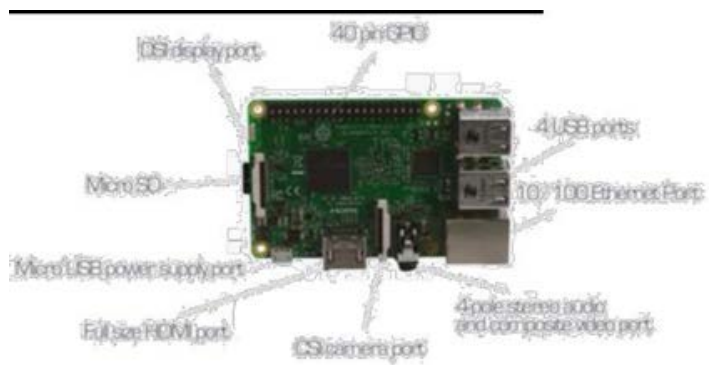

Gambar 12 Spesifikasi Raspberry Pi3.

Raspberry Pi 3 menyediakan 40 pin yang dapat di hubungkan dengan piranti kontrol.

Raspberry tidak menyediakan inputan signal analog sehingga membutuhkanADC ketika sensor memiliki outout analog. ADC digunakan untuk menghubungkan sensor dengan mikrokontroler [7].

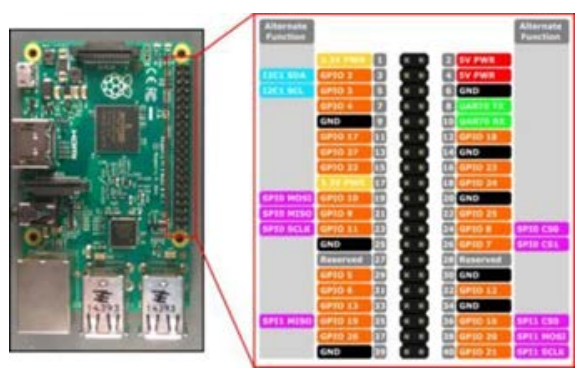

Gambar 13 GPIO Raspberry Pi 3.
Konektor DSI (display Serial Interface) berfungsi sebagai antarmuka secara serial raspberry Pi dengan $L C D$ display controller. Central Procesing Unit menggunakan chip Broadcom BCM 2837 \& 512MB RAM 64 bit Quad Core Processor powered Single Board Computer bekerja pada 1.2GHz 1GB RAM. Micro USB Power Supply Port Micro USB ini memiliki input dengan tegangan $5 \mathrm{~V}$ dan $700 \mathrm{~mA} 5$. Full size HDMI Port. Port HDMI ini bisa di hubungkan ke layar monitor PC/ LCD yang terdapat port HDMI dengan menggunakan kabel HDMI. CSI (Camera Serial Interface) connector berfungsi sebagai antarmuka Raspberry Pi dengan camera yang kompatibel melalui 15 pin serial.

4-pole 3.5mm jack (stereo audio dan composite video port)

10/100 baseT Ethernet Port

4 USB Port

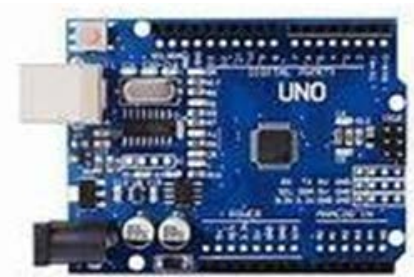

Gambar 14 Arduino Uno,

Arduino adalah Perangkat kerasnya memiliki prosesor yang dimiliki Atmel AVR dan softwarenya memiliki bahasa pemrograman sendiri yaitu program arduino.

Tabel 3 Spesifikasi Arduino Uno.

\begin{tabular}{|l|l|}
\hline Operasi tegangan & 5 Volt \\
\hline Input tegangan & disarankan 7-11Volt \\
\hline $\begin{array}{l}\text { Input tegangan } \\
\text { batas }\end{array}$ & 6-20Volt \\
\hline Pin I/O digital & 14 (6 bisa untuk PWM) \\
\hline Pin Analog & 6 \\
\hline $\begin{array}{l}\text { Arus DC tiap pin } \\
\text { I/O }\end{array}$ & $50 \mathrm{~mA}$ \\
\hline Arus DC 3.3V & $50 \mathrm{~mA}$ \\
\hline Memori flash & $\begin{array}{l}32 \mathrm{~KB} \text { (ATmega328) } \\
\text { dan 0,5 KB digunakan } \\
\text { oleh bootloader }\end{array}$ \\
\hline SRAM & $2 \mathrm{~KB}$ (ATmega328) \\
\hline EEPROM & $1 \mathrm{~KB}$ (ATmega328) \\
\hline Kecepatan clock & $16 \mathrm{MHz}$ \\
\hline
\end{tabular}


RESISTOR (Elektronika Kendali Telekomunikasi Tenaga Listrik Komputer) Vol. 3 No. 2 e-ISSN : 2621-9700, p-ISSN : 2654-2684

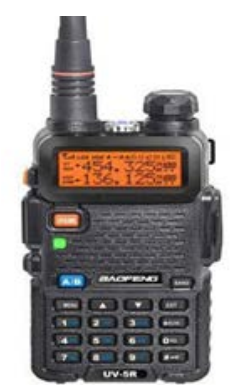

Gambar 15 Handy talky.

Handy talky adalah Alat komunikasi dengan menggunakan frekuensi sebagai komunikasi dan ukuran yang kecil bertujuan agar mudah dibawa dan dipergunakan sebagai komunikasi dilapangan (handheld).

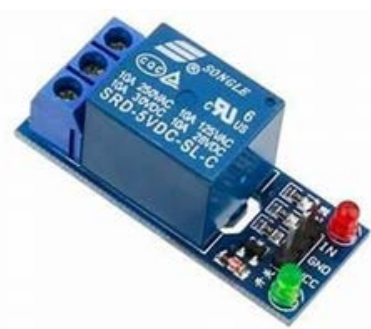

Gambar 16 Modul Relay.

Relay adalah Relay Prinsip Elektromagnetik untuk menggerakkan Kontak Saklar secara otomatis sehingga dengan arus listrik yang kecil (low power) dapat menghantarkan listrik yang bertegangan lebih tinggi. Sebagai contoh, dengan Relay yang menggunakan Elektromagnet 5V dan 50 mA.

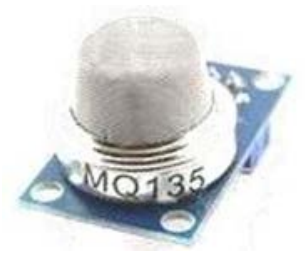

Gambar 17 Sensor MQ-135.

Air quality sensor sebuah modul sensor yang dapat digunakan untuk menentukan kadar konsentrasi gas-gas berbahaya dalam udara. Ada banyak gas yang memiliki efek buruk pada kesehatan manusia [8]. Saat ini ada juga sensor gas yang berbahan semikonduktor organik [9]. Modul ini berbasiskan sensor MQ-135, yaitu sensor yang dapat mendeteksi gas amonia, bensol, alkohol, serta gas berbahaya lainnya. Modul ini cocok digunakan pada proses penentuan kualitas udara (air quality control).

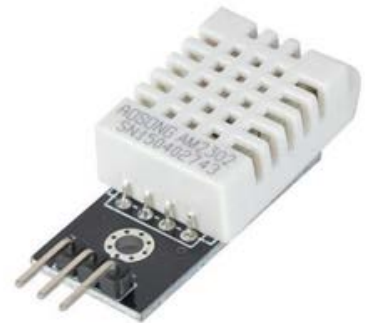

Gambar 18 Sensor DHT 2.

Sensor DHT22 adalah module sensor yang berfungsi untuk mendeteksi objek suhu dan kelembaban yang memiliki output tegangan analog yang dapat diolah lebih lanjut menggunakan mikrokontroler.

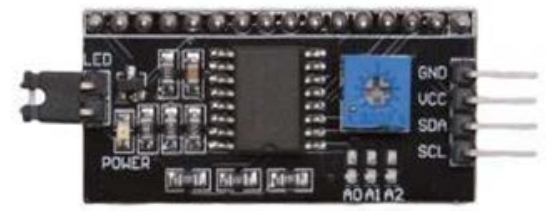

Gambar 19 LCD I2C.

LCD dengan I2C Module untuk Arduino. Inter Integrated Circuit atau sering disebut I2C adalah standar komunikasi serial dua arah menggunakan dua saluran yang didisain khusus untuk mengirim maupun menerima data.

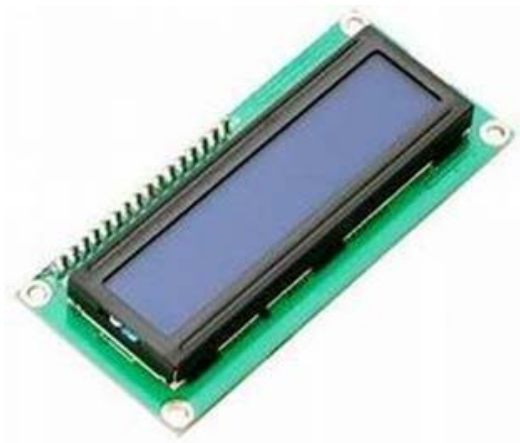

Gambar 20 LCD (Liquid Crystal Display).

LCD (Liquid Crystal Display) adalah suatu jenis media tampil yang menggunakan kristal cair penampil utama. LCD sudah digunakan diberbagai bidang misalnya alal- alat elektronik seperti televisi, kalkulator, atau pun layar komputer.

Fitur LCD 16 x 2 Adapun fitur yang akan disajikan dalam LCD ini adalah :

a. Terdiri dari 16 karakter dan 2 baris.

b. Mempunyai 192 karakter tersimpan.

c. Terdapat karakter generator terprogram.

d. Dapat dialamati dengan mode 4-bit dan 8-bit. 
RESISTOR (Elektronika Kendali Telekomunikasi Tenaga Listrik Komputer) Vol. 3 No. 2 e-ISSN : 2621-9700, p-ISSN : 2654-2684

e. Dilengkapi dengan back light.

Tabel 4 Spesifikasi Kaki LCD 16 x 2 .

\begin{tabular}{|c|c|}
\hline PIN & Deskripsi \\
\hline 1 & Ground \\
\hline 2 & Vcc \\
\hline
\end{tabular}

\section{PERANCANGAN SISTEM}

Pada Bab ini akan di uraikan mengenai perancangan sistem perangkat keras dan lunak. Adapun diagram blok komponen.

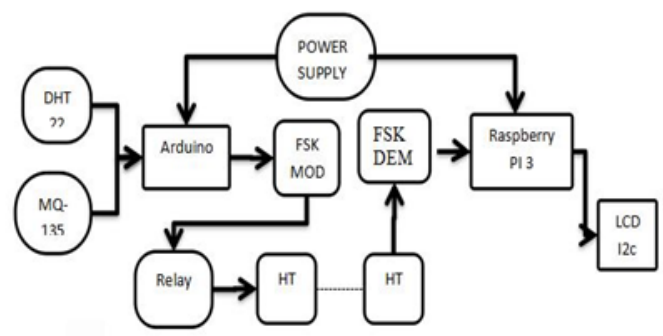

Gambar 21 Gambaran umum alat.

Dari gambar blok diagram diatas terlihat bahwa Handy talky sebagai pengirim dan penerima atau biasa disebut TX dan RX,

Agar dapat terkirim melalui frekuensi dalam Handy talky maka dari itu di perlukan FSK frequency shift keying yaitu modulasi yang merubah karakteristik dan sifat gelombang dengan mengubah frekuensi di dalam nya, dengan begitu data informasi dari mikrokontroler berupa biner dapat terkirim menggunakan Handy talky dan terhubung dengan Handy talky yang lain nya yang di mana handy talky disini bersifat TX (pengirim) dan RX ( Penerima).

Tabel 5 Pin LCD.

\begin{tabular}{|r|l|}
\hline \multicolumn{1}{|l|}{ PIN } & Deskripsi \\
\hline 1 & Ground \\
\hline 2 & Vcc \\
\hline 3 & Pengatur kontras \\
\hline 4 & RS Intruction/ Register Select \\
\hline 5 & R/W Read / White LCD Register \\
\hline 6 & EN Enable \\
\hline $7-14$ & Data I/O Pins \\
\hline 15 & VCC \\
\hline 16 & Ground \\
\hline
\end{tabular}

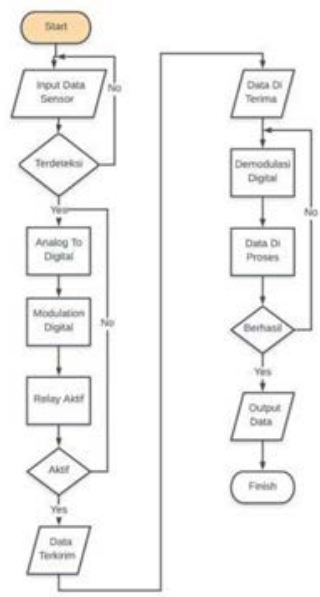

Gambar 22 Sistem kerja alat frequensi shift keying.

Start, Sensor Mendeteksi lingkungan sekitar, Terdeteksi, Data Di Proses melalui Arduino Uno, lalu Data di Modulasi sehingga dikirim melalui frekuensi yang di tumpangi nya melalui frekuensi HT, Data di terima melalui HT kembali, Data di Demodulasi setelah nya data di kirim ke Raspberrry Pi 3, lalu data di proses dan di tampilkan di LCD I2c.

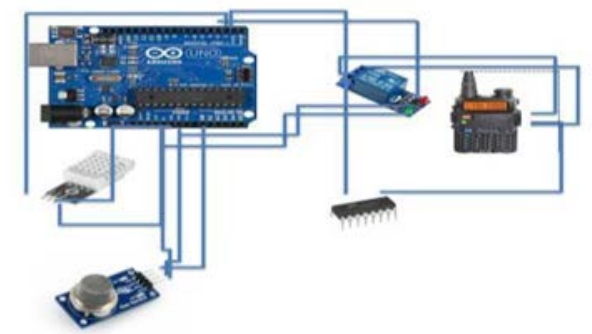

Gambar 23 Rangkaian hardware modulasi FSK.

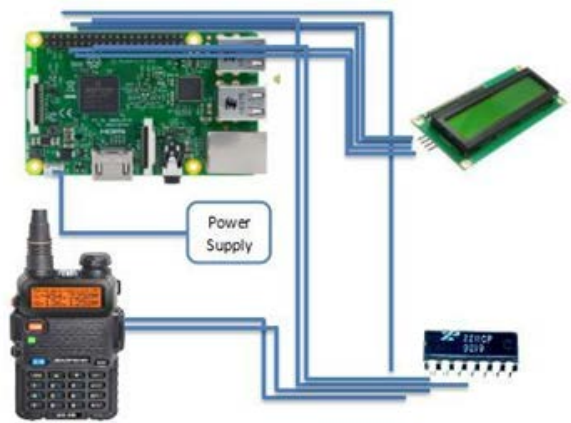

Gambar 24 Rangkaian hardware demodulasi FSK.

\section{UJI COBA DAN ANALISA SYSTEM}

Pada bab ini pengujian dan analisa ini dilakukan agar sesuai dengan yang ingin di lakukan maka di lakukan lah pengujian pada alat sensor.

Proses pengujian Handy Talky, Kelayakan Handy Talky perlu di perhatikan yang dimana Handy Talky nanti nya data akan di kirim melalui frekueansi 
RESISTOR (Elektronika Kendali Telekomunikasi Tenaga Listrik Komputer) Vol. 3 No. 2 e-ISSN : 2621-9700, p-ISSN : 2654-2684

yang di tumpangi nya maka dari itu perlu di perhatikan lagi Handy Talky masih dalam kondisi yang baik.

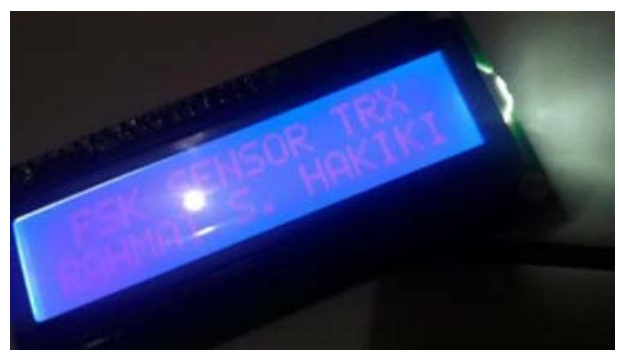

Gambar 25 Tampilan awal output LCD I2C.

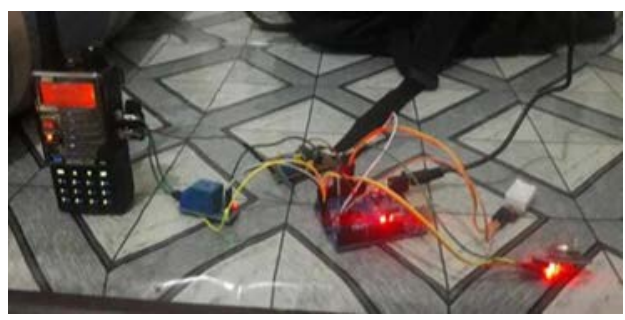

Gambar 26 Rangkaian FSK Modulation.

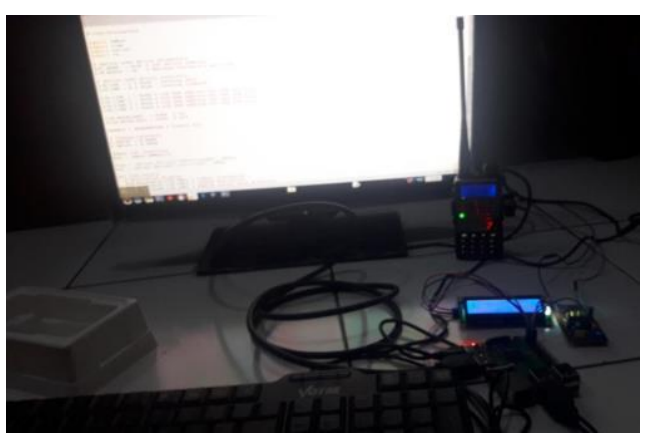

Gambar 27 Rangkaian FSK Demodulation.

Tabel 6 Pengukuran Sensor DHT 22.

\begin{tabular}{|r|c|c|c|c|}
\hline No & $\begin{array}{c}\text { Waktu } \\
{[\mathrm{s}]}\end{array}$ & $\begin{array}{l}\text { Jarak } \\
{[\mathrm{m}]}\end{array}$ & $\begin{array}{l}\text { Frekuensi } \\
\text { HT } \\
{[\mathrm{Hz}]}\end{array}$ & $\begin{array}{l}\text { Data } \\
\text { kelembaban } \\
{[\%]}\end{array}$ \\
\hline 1 & 1 & 10 & 470.625 & 77.50 \\
\hline 2 & 1 & 10 & 470.625 & 68.40 \\
\hline 3 & 1 & 20 & 470.625 & 59.20 \\
\hline 4 & 1 & 30 & 470.625 & 76.20 \\
\hline 5 & 1 & 40 & 470.625 & 77.90 \\
\hline 6 & 1 & 50 & 470.625 & 80.30 \\
\hline 7 & 1 & 60 & 470.625 & 81.00 \\
\hline 8 & 1 & 70 & 470.625 & 82.40 \\
\hline 9 & 1 & 80 & 470.625 & - \\
\hline 10 & 1 & 90 & 470.625 & - \\
\hline
\end{tabular}

Tabel 7 Pengukuran sensor DHT 22.

\begin{tabular}{|r|l|r|r|r|}
\hline No & $\begin{array}{l}\text { Waktu } \\
\text { Transfer } \\
{[\mathrm{s}]}\end{array}$ & $\begin{array}{l}\text { Jarak } \\
{[\mathrm{m}]}\end{array}$ & $\begin{array}{l}\text { Frekuensi } \\
\text { HT }[\mathrm{Hz}]\end{array}$ & $\begin{array}{l}\text { Data } \\
\text { suhu } \\
{\left[{ }^{\circ} \mathrm{C}\right]}\end{array}$ \\
\hline & & & & \\
\hline 1 & 1 & 10 & 470.625 & 30.6 \\
\hline 2 & 1 & 100 & 470.625 & 30.5 \\
\hline 3 & 1 & 200 & 470.625 & 29.8 \\
\hline 4 & 1 & 300 & 470.625 & 29.3 \\
\hline 5 & 1 & 400 & 470.625 & 29 \\
\hline 6 & 1 & 500 & 470.625 & 28.9 \\
\hline 7 & 1 & 600 & 470.625 & 28.7 \\
\hline 8 & 1 & 700 & 470.625 & 28.5 \\
\hline 9 & 1 & 800 & 470.625 & - \\
\hline 10 & 1 & 900 & 470.625 & - \\
\hline
\end{tabular}

$$
\begin{aligned}
\text { Rata-rata } & =\frac{\text { Jumlah data }}{\text { Banyaknya data }} \\
& =\frac{234,5}{8} \\
& =\quad 29,31{ }^{\circ} \mathrm{C}
\end{aligned}
$$

Pengukuran pada 10 - 700 meter memiliki rata rata suhu $29,31{ }^{\circ} \mathrm{C}$.

$$
\begin{aligned}
& \text { Rata-rata }=\frac{\text { Jumlah data }}{\text { Banyaknya data }} \\
& =\frac{602,9}{8} \\
& =\quad 75,36 \%
\end{aligned}
$$

Pengukuran pada 10 - 700 meter memiliki rata rata kelembaban $75,36 \%$.

Tabel 8 Sensor gas MQ-135.

\begin{tabular}{|r|r|r|r|r|}
\hline No & $\begin{array}{c}\text { Waktu } \\
{[\mathrm{s}]}\end{array}$ & $\begin{array}{c}\text { Jarak } \\
{[\mathrm{m}]}\end{array}$ & $\begin{array}{c}\text { Frekuensi } \\
\mathrm{HT} \\
{[\mathrm{Hz}]}\end{array}$ & $\begin{array}{l}\text { Data } \\
\text { Gas } \\
{\left[\mathrm{ppm} / \mathrm{m}^{3}\right]}\end{array}$ \\
\hline 1 & 0.5 & 10 & 470.625 & 1.47 \\
\hline 2 & 1 & 100 & 470.625 & 1.58 \\
\hline 3 & 1 & 200 & 470.625 & 1.14 \\
\hline 4 & 1 & 300 & 470.625 & 1.05 \\
\hline 5 & 1 & 400 & 470.625 & 1.05 \\
\hline 6 & 1 & 500 & 470.625 & 0.96 \\
\hline 7 & 1 & 600 & 470.625 & 1.05 \\
\hline 8 & 1 & 700 & 470.625 & 0.87 \\
\hline 9 & 1 & 800 & 470.625 & - \\
\hline 10 & 1 & 900 & 470.625 & - \\
\hline
\end{tabular}


RESISTOR (Elektronika Kendali Telekomunikasi Tenaga Listrik Komputer) Vol. 3 No. 2 e-ISSN : 2621-9700, p-ISSN : 2654-2684

$$
\begin{aligned}
\text { Rata-rata } & =\frac{\text { Jumlah data }}{\text { Banyaknya data }} \\
& =\frac{9,17}{8} \\
& =1.14 \mathrm{ppm} / \mathrm{m}^{3}
\end{aligned}
$$

Pengukuran sensor gas pada 10 - 700 meter memiliki rata rata $1,14 \mathrm{ppm} / \mathrm{m}^{3}$.

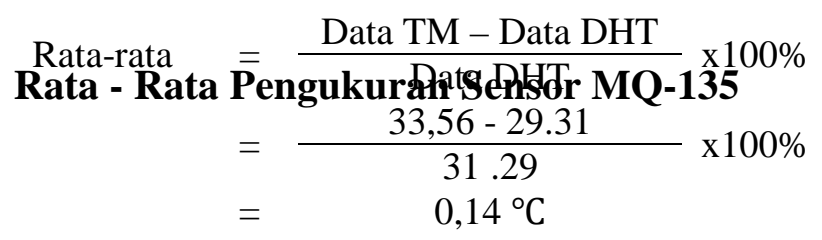

Tabel 9 Perbandingan termometer dengan data suhu DHT 22

\begin{tabular}{|l|l|l|l|l|}
\hline NO & $\begin{array}{c}\text { Waktu } \\
{[\mathrm{s}]}\end{array}$ & $\begin{array}{c}\text { Jarak } \\
\text { (terhalang } \\
\text { gedung) } \\
{[\mathrm{m}]}\end{array}$ & $\begin{array}{c}\text { Data } \\
\text { termo } \\
\text { meter } \\
{\left[{ }^{\circ} \mathrm{C}\right]}\end{array}$ & $\begin{array}{c}\text { Data } \\
\text { suhu } \\
\text { DHT } \\
22 \\
{\left[{ }^{\circ} \mathrm{C}\right]}\end{array}$ \\
\hline 1 & 0.5 & 10 & 32.5 & 30.6 \\
\hline 2 & 1 & 100 & 34 & 30.5 \\
\hline 3 & 1 & 200 & 33.9 & 29.8 \\
\hline 4 & 1 & 300 & 34 & 29.3 \\
\hline 5 & 1 & 400 & 33.7 & 29 \\
\hline 6 & 1 & 500 & 33.6 & 28.9 \\
\hline 7 & 1 & 600 & 33.4 & 28.7 \\
\hline 8 & 1 & 700 & 33.4 & 28.5 \\
\hline 9 & 1 & 800 & - & \\
\hline 10 & 1 & 900 & - & \\
\hline
\end{tabular}

\begin{tabular}{|l|l|l|l|}
\hline $\begin{array}{l}\text { Rata- } \\
\text { rata }\end{array}$ & 33.56 & 29.31 \\
\hline
\end{tabular}

Tabel 10 Perbandingan hygrometer dengan data kelembaban DHT 22.

\begin{tabular}{|l|l|l|l|l|}
\hline No & $\begin{array}{c}\text { Waktu } \\
{[\mathrm{s}]}\end{array}$ & $\begin{array}{c}\text { Jarak } \\
\text { (terhalang } \\
\text { gedung) } \\
{[\mathrm{m}]}\end{array}$ & $\begin{array}{c}\text { Data } \\
\text { hygro } \\
\text { meter } \\
{[\%]}\end{array}$ & $\begin{array}{c}\text { Data } \\
\text { DHT } \\
22 \\
{[\%]}\end{array}$ \\
\hline 1 & 1 & 10 & 76 & 77,5 \\
\hline 2 & 1 & 100 & 84 & 68,4 \\
\hline 3 & 1 & 200 & 81 & 59,2 \\
\hline 4 & 1 & 300 & 79 & 76,2 \\
\hline 5 & 1 & 400 & 72 & 77,9 \\
\hline 6 & 1 & 500 & 72 & 80,3 \\
\hline 7 & 1 & 600 & 74 & 81 \\
\hline 8 & 1 & 700 & 75 & 82,4 \\
\hline 9 & 1 & 800 & - & - \\
\hline 10 & 1 & 900 & - & - \\
\hline & $\begin{array}{l}\text { Rata } \\
\text {-rata }\end{array}$ & & 76,62 & 75,36 \\
\hline
\end{tabular}

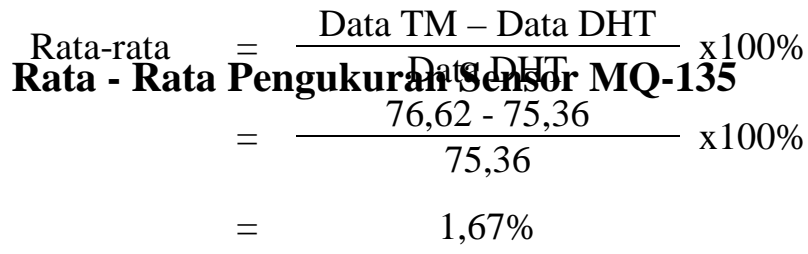

Hasil perbandingannya adalah 1,67 \%.

\section{KESIMPULAN}

Monitoring suhu kelembapan dan gas dengan memanfaatkan spektrum frekuensi radio yang merupakan sumber daya alam yang memiliki nilai strategis ekonomis dan efektif. Hasil pengukuran suhu dengan sensor dht 22 diatas dengan spektrum frekuensi pada jarak $10 \mathrm{~m}$ - $700 \mathrm{~m}$ dengan rata - rata suhu yaitu $30,60{ }^{\circ} \mathrm{C}$ sedangkan pengukuran kelembapan memiliki rata- rata 77,50 \% penggunaan sensor gas mq-135 memiliki rata rata $1,14 \mathrm{ppm} / \mathrm{m}^{3}$. Dengan menggunakan handy talky pengiriman cepat efektif dan metode FSK yang di gunakan mampu meminimalisir noise.

\section{DAFTAR PUSTAKA}

[1] H. Isyanto and D. Arsito, "Sistem Pengaman Rumah dan Peringatan Dini Kebakaran Berbasis SMS dengan Menggunakan Raspberry Pi,” RESISTOR (elektRonika 
RESISTOR (Elektronika Kendali Telekomunikasi Tenaga Listrik Komputer) Vol. 3 No. 2 e-ISSN : 2621-9700, p-ISSN : 2654-2684

kEndali telekomunikaSI tenaga liSTrik kOmputeR), vol. 1, no. 1, pp. 13-24, 2018.

[2] H. Muchtar and T. Firmansyah, "PERANCANGAN DAN SIMULASI ANTENA HELIX PADA FREKUENSI 2, 4 GHZ,” eLEKTUM, vol. 15, no. 2, 2018.

[3] H. Hendrianto, "SISTEM REMOTE MONITORING GEDUNG BERBASIS MIKROKONTROLER MELALUI RADIO FREKUENSI HT," Universitas Kristen Maranatha, p. 6.

[4] K. Dharma, "PERANCANGAN PROTOTYPE SISTEM MONITORING GEMPA MENGGUNAKAN SENSOR INERTIAL MEASUREMENT UNIT (IMU) DAN PEMANFAATAN METODE FREQUENCY SHIFT KEYING (FSK) MELALUI FREKUENSI HANDY TALKY (HT)," JURNAL SISTEM KOMPUTER, 2014, Accessed: Jul. 27, 2020. [Online]. Available: http://repo.unand.ac.id/757/.

[5] A. Goeritno and R. Yatim, "Modifikasi Modem pada Jaringan APRS untuk Pengiriman dan Penerimaan Data Paket Telemetri,” Universitas Ibn Khaldun, 2014.

[6] M. Rizki and R. Amri, "Perancangan Kontrol dan Monitoring Level Ketinggian Air di Waduk Bagian Hulu Untuk Meningkatkan Efektifitas Kinerja PLTA Koto Panjang,” Riau University, 2016.

[7] J. Pramono, T. Susila, and P. B. Mardjoko, "Perancangan Alat Telemetri Temperatur dan Gas Pada Gunung Berapi Secara Wireless," TESLA: Jurnal Teknik Elektro, vol. 17, no. 1, pp. 88-103, 2017.

[8] K. S. Babu and C. Nagaraja, "Calibration of MQ-7 and Detection of Hazardous Carbon Monoxide Concentration in Test Canister," International Journal of Advance Research, Ideas and Innovations in Technology, vol. 4, no. 1, pp. 18-24, 2018.

[9] F. Fadliondi and B. Budiyanto, "Transistor Efek Medan Berbasis Semikonduktor Organik Pentacene untuk Sensor Kelembaban,” Jurnal Nasional Teknik Elektro dan Teknologi Informasi, vol. 6, no. 2, pp. 204-209, 2017. 